\title{
Message from Organizing and Editorial Team IFCPC 2021
}

\section{Saritha Shamsunder ${ }^{1}$}

Published online: 2 June 2021

(C) Association of Gynecologic Oncologists of India 2021

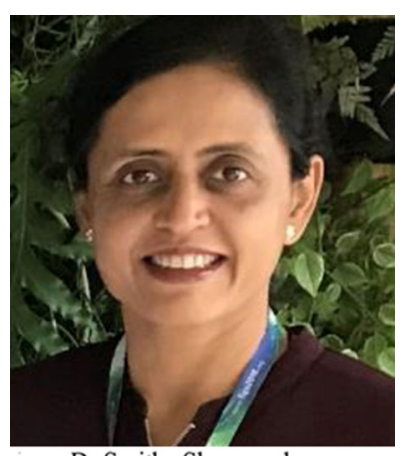

Dr Saritha Shamsunder Organizing chairpersonIFCPC 2021

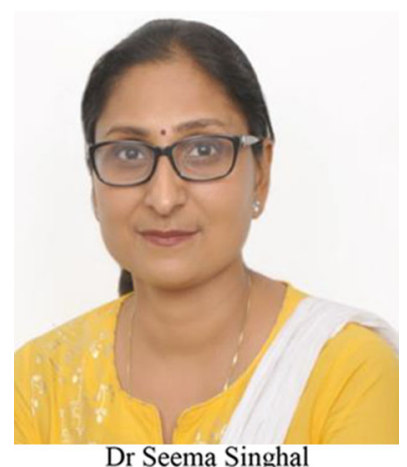

Editorial team, IFCPC 2021

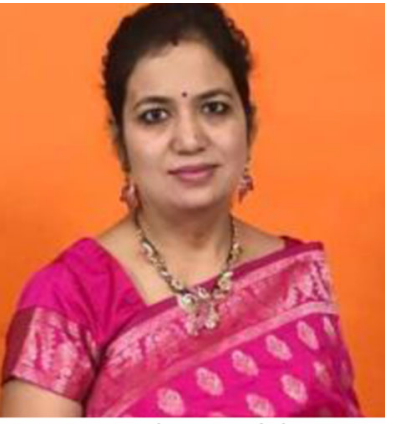

Dr Archana Mishra Organising Secretary, IFCPC 2021

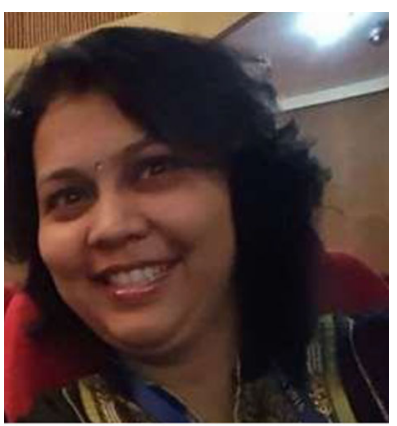

Dr Bindiya Gupta Editorial team, IFCPC 2021

Saritha Shamsunder shamsundersaritha@gmail.com

1 Vardhmaan Mahaveer Medical College \& Safdarjung Hospital, New Delhi, India 
Dear Colleagues and Friends,

We are excited to host the " 17 th World Congress of the International Federation of Colposcopy \& Cervical Pathology", a triennial world congress. This is a unique meeting as it is being held for the first time in Asia, hosted by the Indian Society of Colposcopy \& Cervical Pathology. We look forward to welcoming you all on the virtual platform. The scientific sessions are focused on the conference theme "Eliminating Cervical Cancer-Call for Action". More than 100 eminent faculties from all over the world will present their viewpoints, experiences, and research on various aspects of cervical cancer. This meeting will be a unique platform to bring all the stake holders together, to formulate strategies to turn our dream of eliminating cervical cancer into reality.

In line with the IFCPC mission of stimulating basic and applied research and the dissemination of knowledge related to cervical pathology and colposcopy, the key topics for discussion range from epidemiology, basic sciences, screening, innovations to public health, quality assurance and psychosocial impact of disease.

We bring this special Issue of "Indian Journal of Gynecologic Oncology" which features review articles from renowned international speakers and abstracts of cutting-edge research in the field of cervical cancer. We express our sincere gratitude to the Chief Editor, Dr Somashekhar SP and office bearers of Association of Gynaecological Oncologists of India to facilitate this special issue. We are encouraged by the overwhelming response from researchers in all categories and deeply indebted to the reviewers for painstakingly reviewing all the abstracts. We hope our readers will benefit from this treasure trove of information get energized to develop solutions for Eliminating Cervical Cancer by 2030.

Publisher's Note Springer Nature remains neutral with regard to jurisdictional claims in published maps and institutional affiliations. 